\title{
O CONCEITO DE VALÊNCIA EM LIVROS DIDÁTICOS DE QUÍMICA GERAL ENTRE AS DÉCADAS DE 1890 E
} 1940

\author{
Helena S. Alvares Nogueira ${ }^{\mathrm{a}, *}$ e Paulo Alves Porto
}

anstituto de Química, Universidade de São Paulo, 05508-000 São Paulo - SP, Brasil

bDepartamento de Química Fundamental, Instituto de Química, Universidade de São Paulo, 05508-000 São Paulo - SP, Brasil

Recebido em 30/05/2018; aceito em 18/10/2018; publicado na web em 28/11/2018

\begin{abstract}
THE CONCEPT OF VALENCE IN GENERAL CHEMISTRY TEXTBOOKS FROM THE 1890s TO THE 1940s. This paper aims to investigate the presentation of the concept of valence in college-level, general chemistry textbooks published in the USA between the 1890s and the 1940s. The delimited period covers the emergence of theories about atomic structure, electronic distribution and chemical bonding. Transition from the classical concept of valence (as the combining power of a chemical element), which resulted from either the analysis of formulas of compounds or experimental results, into the concept related to the electronic structure of elements, according to which the valence is determined by the number of electrons in the last shell, was observed. In general, valence was presented in textbooks in order to serve as an instrument for the writing of formulas of compounds, and historical approaches to the construction of the concept were not contemplated by the authors.
\end{abstract}

Keywords: general chemistry; textbooks; valence; higher education; chemistry teaching; history of chemistry.

\section{INTRODUÇÃO}

Os livros didáticos para o ensino superior revestem-se de reconhecida importância no processo de formação de novos cientistas e professores. ${ }^{1,2}$ Já foi observado que os livros didáticos exercem grande influência sobre os estudantes e professores, sendo considerados inquestionáveis por muitos deles. ${ }^{3,4}$ Apesar disso, ainda há uma carência nas investigações científicas sobre livros didáticos para o ensino superior quanto a aspectos ontológicos e epistemológicos dos conceitos químicos, e suas implicações para o processo de ensino-aprendizagem. ${ }^{5,6}$

De acordo com a concepção de Kuhn, os livros didáticos são responsáveis pela transmissão dos paradigmas aceitos e da linguagem usada pela comunidade científica da época em que foram publicados, exercendo, por isso, papel fundamental na formação de novos cientistas e profissionais. ${ }^{1}$ Choppin, por sua vez, destaca que os livros didáticos são também responsáveis, além do suporte à transmissão dos conhecimentos considerados necessários, por permitir a prática de métodos didáticos, a construção de uma identidade de grupo, e pelo desenvolvimento do espírito crítico das novas gerações. ${ }^{7}$ Além disso, vale ressaltar que os livros didáticos sofrem pressões políticas, sociais e econômicas e que, para serem publicados e utilizados, precisam ser negociados entre o autor, o público (professores e universidades), a mídia (editoras) e o Estado ${ }^{5,8}$ Dessa forma, esses aspectos justificam que os livros didáticos sejam tomados como fontes históricas para caracterizar a ciência e seu ensino em uma determinada época.

Trabalhos recentes buscaram relacionar a análise de livros didáticos de química à história da ciência, sob diferentes perspectivas. Niaz, ${ }^{9}$ Fernandes e Porto ${ }^{10}$ e Leite e Porto ${ }^{11}$ investigaram a inclusão de aspectos da história da ciência no conteúdo dos livros, mas os resultados apontaram para a ausência de questões históricas na maioria das obras analisadas e para a superficialidade na abordagem dessas questões, quando estão presentes. Niaz investigou a apresentação da teoria cinética molecular dos gases em livros didáticos para o ensino médio publicados nos EUA no final do século $\mathrm{XX} .{ }^{9}$ Fernandes e Porto investigaram como a história da química é abordada em alguns

*e-mail: helena.savignani.leite@usp.br dos livros didáticos mais recomendados em cursos de química de nível superior no Brasil. ${ }^{10}$ Leite e Porto, por sua vez, investigaram a apresentação da tabela periódica em livros de química geral voltados para o ensino superior, publicados no Brasil ao longo do século XX. ${ }^{11}$ Esses trabalhos evidenciam algumas das dificuldades do processo de ensino e aprendizagem dos conceitos e, principalmente, do fazer ciência, causadas pela ausência e superficialidade da abordagem histórica utilizadas pelos livros didáticos.

O presente artigo adota um viés investigativo semelhante ao de Leite e Porto. ${ }^{11}$ Nosso objetivo é analisar a apresentação do conceito de valência em uma amostra de livros didáticos para o ensino superior publicados nos EUA entre a última década do século XIX e as primeiras décadas do século passado. A escolha se justifica pela influência dos EUA na construção da ciência e no desenvolvimento de diversas teorias químicas no período adotado para estudo. Nessa época, o conceito de valência, que desempenhava papel relevante no corpo do conhecimento químico, sofreu modificações em função do desenvolvimento das teorias sobre a estrutura atômica. Assim, partimos da suposição de que os livros precisaram desenvolver estratégias para conciliar sua natural tendência conservadora (ou de inserção no paradigma vigente, na concepção kuhniana) com as novas teorias que foram se desenvolvendo no início do século XX e que mudaram bastante a química. Em particular, procuramos investigar as mudanças na valência no contexto das teorias sobre estrutura, ligação química e periodicidade química. É preciso considerar que mudanças nas teorias podem implicar em mudanças nas formas de representação, incluindo a linguagem e a nomenclatura. Além disso, uma das possíveis estratégias didáticas para conciliar continuidades e rupturas em um momento de transformação na ciência é abordar a história do desenvolvimento dos conceitos, o que nos motivou a investigar o uso dessa estratégia na amostra considerada. Dessa forma, buscamos fornecer contribuições para a compreensão do processo que envolve a consolidação e a difusão do conhecimento químico por meio dos livros didáticos.

\section{A IMPORTÂNCIA DO CONCEITO DE VALÊNCIA}

De acordo com o Compendium of Chemical Terminology (ou Gold Book) da IUPAC, valência é "the maximum number of 
univalent atoms (originally hydrogen or chlorine atoms) that may combine with an atom of the element under consideration, or with a fragment, or for which an atom of this element can be substituted" [o número máximo de átomos univalentes (originalmente, átomos de hidrogênio ou cloro) que podem se combinar com um átomo do elemento sob consideração, ou com um fragmento, ou pelo qual um átomo desse elemento pode ser substituído]. ${ }^{12} \mathrm{O}$ termo "valência" também é utilizado como adjetivo em expressões como camada de valência, elétrons de valência e ligação de valência, por exemplo. Assim, esse termo é usado em várias áreas da química, ainda que a definição clássica pareça não dar conta, à primeira vista, de todos os contextos em que a palavra é empregada.

$\mathrm{O}$ conceito de valência (que inicialmente foi designado por outros nomes) já era considerado importante nas investigações sobre a composição e estrutura da matéria desde a segunda metade do século XIX. Nessa época, o conceito de valência estava relacionado à ideia de afinidade química e à existência de alguma coisa que fizesse determinados elementos ficarem juntos - ainda que suas causas fossem desconhecidas. Por muito tempo, a valência foi considerada como sinônimo de ligação química, ou como sua causa.

A importância do conceito de valência no processo de desenvolvimento da química foi assim sumarizada por Araújo Neto:

A noção de valência é um tema ao mesmo tempo controverso e central na história da Química. Por meio das diferentes aproximações desenvolvidas para precisar o seu papel no desenvolvimento do conhecimento químico, a noção de valência demonstrou ser pelo menos uma estratégia metodológica bastante eficiente para aproximação do químico com o misterioso mundo interior da transformação química. Essa noção se atreveu a tentar explicar os antigos domínios da afinidade química, produzindo com isso uma maneira especial de representar a realidade invisível dos átomos e das moléculas mediante as chamadas fórmulas estruturais. Sua influência encontra-se registrada na inauguração tanto do programa de pesquisa da química orgânica, por meio dos trabalhos de Laurent, Gerhardt e Kekulé, entre outros, quanto na forte colaboração para a formulação das hipóteses explicativas da relação estrutura-propriedade dos complexos de Werner. Como se não bastasse, a valência provocou também o mundo periódico, organizando a posição dos primeiros elementos tanto no sistema russo, proposto por Mendeleev, como no alemão, proposto por Meyer. A partir de todas essas influências, professores de Química concordam que é impossível dar os primeiros passos na disciplina sem ser apresentado a ela (p. 13). ${ }^{13}$

Tendo em vista a importância do conceito de valência no desenvolvimento da química, e também no contexto do ensino dessa ciência, entendemos ser relevante a investigação de sua presença em livros didáticos. A metodologia adotada e os resultados obtidos nessa investigação são apresentados a seguir.

\section{METODOLOGIA}

A análise dos livros didáticos utilizou elementos da análise textual discursiva, de forma semelhante à utilizada por Pimentel. ${ }^{14}$ De acordo com essa metodologia, primeiramente, são escolhidos os livros a serem analisados; em seguida, o material é organizado, destacando-se o que se considera mais importante para a pesquisa, por meio de uma primeira leitura, fichamento dos livros e seleção das unidades de análise. A organização, leituras e análises do material sofrem, então, sucessivas revisões e reelaborações até o final da pesquisa, conforme os critérios e as categorias criadas no processo de análise dos documentos. Por fim, é feita uma análise das categorias criadas (devem ser internamente homogêneas, externamente heterogêneas, coerentes e plausíveis), por meio de interpretações e inferências dos pesquisadores, resultando numa síntese de tudo aquilo que foi encontrado.

Essa metodologia foi escolhida por permitir duas reconstruções concomitantes, relevantes para o estudo, de acordo com Moraes e Galiazzi: as reconstruções " 1 . do entendimento de ciência e de seus caminhos de produção. 2. do objeto da pesquisa e de sua compreensão". ${ }^{15}$ Dessa forma, a análise textual discursiva pode ser útil em estudos de história da ciência, pois permite estudar e compreender o assunto rompendo com ideias e interpretações já existentes, bem como permite verificar mudanças nas diferentes categorias de análise construídas. Além disso, a análise textual discursiva propicia um trabalho investigativo constante. Ao longo do processo, são reconstruídos conceitos e visões, e são reinterpretados os materiais já analisados e reanalisados constantemente, partindo do princípio de que, no início da pesquisa, não se tem uma visão clara e completa do que se vai encontrar.

Os livros didáticos analisados foram selecionados a partir de um conjunto de obras localizadas na biblioteca da Chemical Heritage Foundation ( $C H F$, Filadélfia, EUA), uma instituição dedicada à preservação da memória sobre a química nos EUA. Em estágio de pesquisa realizado entre junho e julho de 2015, o segundo autor deste trabalho fez um levantamento de livros didáticos de química geral publicados nos EUA entre 1890 e 1959 disponíveis na biblioteca da CHF. O total de livros foi delimitado buscando-se localizar sua presença também nos catálogos de bibliotecas de algumas universidades estadunidenses selecionadas, destacadas pela pesquisa e ensino de química no século passado (a saber: Harvard University, Johns Hopkins University, University of Wisconsin-Madison e University of California - Los Angeles). Assim, chegou-se a uma amostra de 84 livros, em geral presentes em duas ou mais das instituições consultadas, os quais foram copiados em parte, ou baixados na íntegra quando disponíveis na Internet. Dessa amostra foram pré-selecionados 62 livros do período compreendido entre 1894 e 1949 , que apresentavam e discutiam o conceito de valência. Sobre essa amostra foi feita uma primeira análise, e dela foram selecionados, para análise mais aprofundada, os livros mais representativos de cada década ou abordagem.

Foi encontrada uma quantidade significativa de livros para cada década. A análise dos livros visou identificar as características do ensino e suas modificações ao longo do tempo. O período de abrangência da pesquisa foi definido considerando a relevância do conceito de valência no contexto do ensino, sendo que, a partir do final dos anos 1940, as explicações eletrônicas e quânticas para conceitos clássicos da química ganharam força, com a gradativa substituição de um conceito abrangente de valência por outros derivados dele. Além disso, também optamos por não avançar no período posterior ao lançamento do Sputnik (1957), considerado como um marco que levou a reflexões sobre o ensino de ciências em geral (incluindo o ensino de química) no Ocidente e ao surgimento de diferentes projetos para a reformulação desse ensino.

A Tabela 1 mostra a distribuição da quantidade de livros por década em nossa amostra.

A análise dos livros foi feita de acordo com critérios propostos a partir de leituras preliminares do material, descritos no Quadro 1. Esses critérios se voltam para a investigação da natureza do conceito de valência, a presença ou ausência da história do conceito, qual a abordagem e a relevância dada ao conceito, e qual a posição em que o conceito se encontra no texto em relação a outros conceitos relacionados (como a tabela periódica dos elementos, por exemplo). Nesse 
Tabela 1. Distribuição dos livros didáticos por década

\begin{tabular}{lcccccc}
\hline Década & 1890 & 1900 & 1910 & 1920 & 1930 & 1940 \\
\hline Quantidade de livros & 5 & 8 & 12 & 15 & 10 & 12 \\
\hline
\end{tabular}

Quadro 1. Critérios de análise do material didático

\begin{tabular}{|c|c|}
\hline Critério & Descrição \\
\hline $\begin{array}{l}\text { Localização e frequência } \\
\text { do conceito }\end{array}$ & $\begin{array}{l}\text { Busca identificar a localização do conceito no livro, a quantidade de vezes que o conceito aparece e o espaço dedicado a } \\
\text { ele, uma vez que esses aspectos indicam a importância que o autor do livro atribui ao conceito. }\end{array}$ \\
\hline Nomenclatura e notação & $\begin{array}{l}\text { A nomenclatura e a notação da valência sofreram modificações ao longo do tempo; portanto, podem indicar se o conceito } \\
\text { utilizado é mais antigo ou mais moderno. } \\
\text { A palavra valência tem origem no termo latino valens, relacionado à ideia de "força". Historicamente, a valência foi } \\
\text { entendida como um "poder de combinação" característico de cada elemento químico, mas alguns químicos do final do } \\
\text { século XIX usavam esse termo como sinônimo de ligação química (isto é, uma relação entre dois átomos). Para tentar } \\
\text { estabelecer uma distinção, alguns autores de língua inglesa usavam a grafia valency para indicar o poder de combinação } \\
\text { dos átomos, e valence para indicar a união entre dois átomos. Não chegou, porém, a existir consenso sobre essa distinção. }{ }^{16}\end{array}$ \\
\hline Definição & O conceito de valência se modificou ao longo do tempo, e a definição utilizada no livro indica a qual conceito se refere. \\
\hline $\begin{array}{l}\text { Determinação do valor } \\
\text { da valência }\end{array}$ & Busca identificar a importância dada pelo autor do livro a aspectos empíricos e práticos relacionados ao conceito de valência. \\
\hline História do conceito & $\begin{array}{l}\text { Busca verificar se há alguma contextualização da construção do conceito e discussão sobre as modificações sofridas, assim } \\
\text { como a relação com a química orgânica, em cujo âmbito o conceito de valência inicialmente surgiu. }\end{array}$ \\
\hline Relação com outras teorias & $\begin{array}{l}\text { Busca verificar se os autores mostram a dependência entre conceitos e a relação da valência com teorias sobre estrutura, } \\
\text { ligação química e periodicidade. }\end{array}$ \\
\hline Usos e aplicações & $\begin{array}{l}\text { Busca verificar a razão pela qual o autor apresenta o conceito, ou seja, qual sua função no contexto do livro e se esta } \\
\text { também se modificou ao longo do tempo. }\end{array}$ \\
\hline
\end{tabular}

processo, se procurou investigar as mudanças nos livros didáticos e suas relações com mudanças na própria ciência química durante as primeiras décadas do século XX.

\section{ANÁLISE DOS LIVROS DIDÁTICOS DE QUÍMICA GERAL}

Foi realizada uma análise preliminar de um total de 62 livros, os quais foram agrupados por décadas e tiveram delineadas as principais características de suas abordagens para o conceito de valência. Em seguida, foram selecionados dez livros, considerados mais representativos das diferentes tendências e abordagens identificadas, os quais foram objeto de análise mais aprofundada. As seções que se seguem trazem a análise geral das tendências em cada década,bem como a análise mais detalhada de como o conceito de valência foi apresentado nos dez livros escolhidos.

\section{Anos 1890}

Desse período, foram analisados os seguintes livros: Attfield (1894), Freer (1894), Sadtler e Trimble (1895), Ostwald (1895) e Long (1898). ${ }^{17-21} \mathrm{O}$ Quadro 2 sumariza as características observadas nesse conjunto de livros.

De modo geral, os livros da década de 1890 apresentam a valência como uma propriedade numérica e periódica dos elementos químicos, a qual indica a capacidade de combinação dos respectivos átomos, sendo apresentada no início do livro entre outros conceitos básicos, e é indicada por números romanos.

Desse período foi analisado em maior profundidade o livro de Attfield, ${ }^{17}$ por ser o livro mais antigo e mostrar uma visão peculiar da química. Logo no prefácio, o autor enumera as razões pelas quais se deve ensinar e estudar química: segundo Attfield (p. viii), a química é

Quadro 2. Abordagem do conceito de valência na década de 1890

\begin{tabular}{|c|l|}
\hline Critério & \multicolumn{1}{|c|}{ Década de 1890 } \\
\hline $\begin{array}{c}\text { Localização e frequência } \\
\text { do conceito }\end{array}$ & Início do livro \\
\hline $\begin{array}{c}\text { Nomenclatura e notação } \\
\text { Monovalente, divalente, etc. } \\
\text { Números romanos. }\end{array}$ \\
\hline Definição & Capacidade de combinação de um átomo, expressa como propriedade numérica. Valores apresentados em tabelas. \\
\hline $\begin{array}{c}\text { Determinação do valor } \\
\text { da valência }\end{array}$ & Análise das fórmulas dos compostos nos quais o elemento aparece. \\
\hline História do conceito & Não aparece de forma significativa. \\
\hline $\begin{array}{c}\text { Relação com outras teorias } \\
\text { Quatro dos cinco livros apresentam a valência como uma propriedade periódica e relacionam seu valor numérico com o } \\
\text { número do grupo da tabela periódica ao qual o respectivo elemento pertence. Esses livros ressalvam haver certa dificuldade } \\
\text { com alguns poucos elementos, que possuem mais de um valor para a valência. Dois livros apresentam essa variação como } \\
\text { algo ainda em estudo, que aguardaria por ser mais bem explicada em um futuro próximo. }{ }^{17,20}\end{array}$ \\
\hline Usos e aplicações & $\begin{array}{l}\text { Determinação de outras fórmulas químicas, produtos de reações e do número de combinações (ligações) que um elemento } \\
\text { pode realizar. }\end{array}$ \\
\hline
\end{tabular}


um "instrumento da cultura mental", que aguça e expande o poder da observação, amplia e fortalece a memória e a imaginação, desenvolve e elabora o pensamento e a razão. ${ }^{17}$

Nesse livro, o conceito de valência é apresentado no capítulo 4, intitulado "Os princípios gerais da filosofia química". A valência é definida como o "valor" do átomo, de forma análoga aos valores de moedas e notas. $\mathrm{O}$ autor ressalta que há vários nomes para esse conceito, sendo que ele opta por quantivalence ou valency. Attfield também destaca que esse conceito não está relacionado com a intensidade da união dos átomos nem com a estabilidade de compostos, e que os valores das valências devem ser decorados para facilitar a escrita correta de fórmulas, e para isso são fornecidos valores em tabelas. Por fim, Attfield apresenta elementos com mais de uma valência, como o ferro, observando que, naquele momento, não havia uma explicação científica para tal fato. ${ }^{17}$

Dois aspectos do livro de Attfield chamam a atenção. O autor enfatiza bastante o fato de a química trabalhar com modelos - como os de átomo e as fórmulas estruturais dos compostos - que são entes hipotéticos e não objetos reais. Outro aspecto observado é que o autor usa vários termos para o conceito de valência, nomeado ao longo da obra como quantivalence, valency e valence, de forma indiscriminada $\mathrm{e}$, às vezes, em uma mesma seção. ${ }^{17}$

\section{Anos 1900}

Desse período, foram analisados os seguintes livros: Fetterolf (1900), Tillman (1904), McPherson e Henderson (1906), Pond (1906), Brownlee (1907), Smith (1908), Baskerville (1909) e Ostwald (1909). ${ }^{22-29}$ O Quadro 3 sumariza as características observadas nesse conjunto de livros.

De modo geral, o conceito de valência é apresentado nos livros da década de 1900 como poder de combinação dos elementos e como uma das propriedades periódicas, com valores tabelados obtidos pela análise de fórmulas, sendo apresentado no início dos livros. Os compostos são caracterizados como saturados ou insaturados, conforme o uso total ou parcial da valência do elemento considerado.

Desse período, foi analisado em maior profundidade o livro de McPherson e Henderson, ${ }^{24}$ por apresentar um capítulo exclusivo sobre valência (capítulo 11 - Valence), o qual se segue à apresentação de vários conceitos químicos, como átomo, lei das proporções definidas, pesos atômicos e moleculares e cálculo estequiométrico. Nesse capítulo, define-se o conceito de valência como uma propriedade numérica do elemento, a qual determina o número de átomos com que o elemento irá se combinar. McPherson e Henderson ressaltam que a valência é apenas um número, uma grandeza qualitativa, e que não está relacionada com a intensidade da união ou afinidade entre os elementos. Os autores partem da análise de fórmulas para chegar aos valores das valências e depois usam esses números para escrever outras fórmulas e prever produtos de reação (atividade que é feita não só pelos autores no corpo do texto, mas também nos exercícios propostos ao final do capítulo). A análise de fórmulas relacionada à valência é feita novamente no capítulo sobre a tabela periódica, para demonstrar que essa é uma das propriedades periódicas. ${ }^{24}$

Merece destaque nesse livro, a seguinte afirmação feita pelos autores:

We have no knowledge as to why elements differ in their combining power, and there is no way to determine their valences save by experiment (p. 118). [Não temos conhecimento do porquê os elementos diferirem em seu poder de combinação, e não há outro modo de se determinar suas valências senão por experimentos.] $]^{24}$

Nesse trecho, os autores deixam claro que a natureza da valência era, então, desconhecida, e que esse conceito era empírico, baseado apenas em resultados de experimentos. A mesma justificativa é dada para os elementos que apresentam mais de um valor para a valência, sendo observado que sempre há um valor mais comum que forma compostos mais estáveis. ${ }^{24}$

O livro de McPherson e Henderson traz princípios químicos junto com aplicações práticas. Porém, os autores afirmam, no prefácio, que seu livro apresenta uma forma simplificada e parcial dos conceitos, com o intuito de fornecer uma base para o estudante avançar com maior facilidade em estudos mais aprofundados, uma vez que existe uma grande distância entre as fronteiras da ciência e o aluno

Quadro 3. Abordagem do conceito de valência na década de 1900

\begin{tabular}{|c|c|}
\hline Critério & Década de 1900 \\
\hline $\begin{array}{l}\text { Localização e frequência } \\
\text { do conceito }\end{array}$ & $\begin{array}{l}\text { Em geral, o conceito de valência é apresentado no início desses livros, em capítulos introdutórios, como uma das proprie- } \\
\text { dades químicas. Apenas McPherson e Henderson dedicam à valência um capítulo específico. }{ }^{24}\end{array}$ \\
\hline Nomenclatura e notação & $\begin{array}{l}\text { Todos usam o termo valence. } \\
\text { Exceto McPherson e Henderson, }{ }^{24} \text { Brownlee }^{26} \text { e Smith, }{ }^{27} \text { todos utilizam a nomenclatura monovalente, divalente, etc. } \\
\text { Tillman } n^{23} \text { e McPherson e Henderson }{ }^{24} \text { utilizam números romanos e, também, traços entre os elementos (como nas fórmulas } \\
\text { estruturais planas); Pond }{ }^{25} \text { e Ostwald }{ }^{29} \text { utilizam apenas os traços. Os demais livros não utilizam uma notação específica } \\
\text { para o conceito. }\end{array}$ \\
\hline Definição & Exceto Ostwald, ${ }^{29}$ todos definem valência como poder de combinação, usando o hidrogênio como unidade. \\
\hline $\begin{array}{l}\text { Determinação do valor } \\
\text { da valência }\end{array}$ & $\begin{array}{l}\text { Análise das fórmulas dos compostos químicos, considerando a proporcionalidade entre átomos e massas, }{ }^{22-28} \text { mas apenas } \\
\text { Smith }^{27} \text { e McPherson e Henderson }{ }^{24} \text { explicam o modo de fazer essa determinação. }\end{array}$ \\
\hline História do conceito & $\begin{array}{l}\text { Apenas em Ostwald aparece de forma significativa, ao mencionar questões em aberto sobre isomerismo e apresentar as } \\
\text { chamadas fórmulas estruturais como o nome dado aos desenhos dos compostos nos quais a valência é representada por } \\
\text { traços. } .^{29} \text { Pond é o único autor do período a citar o termo "ligação" como sinônimo de valência, sem maiores explicações. }{ }^{25}\end{array}$ \\
\hline Relação com outras teorias & $\begin{array}{l}\text { Exceto Ostwald }{ }^{29} \text { todos apresentam a valência como uma propriedade periódica, alguns com mais detalhes (exemplos de } \\
\text { fórmulas) e outros apenas citando a valência característica de cada grupo da tabela periódica. Todos ressaltam que o valor } \\
\text { apresentado na tabela periódica é um valor máximo, uma vez que os elementos podem ter a valência variável, ou seja, } \\
\text { usar totalmente sua valência (formando os compostos ditos saturados) ou usá-la apenas parcialmente (originando, assim, } \\
\text { compostos insaturados), conforme as condições da formação do composto e os elementos envolvidos. }\end{array}$ \\
\hline Usos e aplicações & $\begin{array}{l}\text { Determinação de outras fórmulas químicas, produtos de reações e do número de combinações (ligações) que um elemento } \\
\text { pode realizar. }\end{array}$ \\
\hline
\end{tabular}


iniciante. ${ }^{24}$ Essa ressalva é relevante e mostra uma preocupação dos autores, na época, que permanece atual, considerando que a referida distância aumentou ao longo do último século.

\section{Anos 1910}

Foram analisados os seguintes livros desse período: Molinari (1912), Newell (1912, 1914), Pond (1912), Blake (1913), Jones (1913), McPherson e Henderson (1913, 1915, 1917), Cady (1916), Smith (1916) e Hildebrand (1918). ${ }^{30-41}$ O Quadro 4 sumariza as características observadas nesse conjunto de livros.

Todos os livros analisados da década de 1910 definem a valência como poder de combinação, sendo usada para escrever fórmulas e reações químicas. É apresentada no início dos livros, como um dos conceitos fundamentais para a continuidade da abordagem da química nos capítulos que se seguem. A maioria dos livros aponta que Mendeleev já considerava a valência como uma propriedade periódica, embora reconheçam que é preciso estar atento ao fato de que a valência de um elemento pode variar - gerando compostos saturados e insaturados, conforme o uso total ou parcial de suas valências.

Desse período, destacamos aqui o livro de Molinari, ${ }^{30}$ pois ele se diferencia dos outros por ser um livro italiano traduzido para o inglês (o que é raro) e por apresentar um pouco de contextualização histórica para o conceito de valência. Interessante notar que o livro traz uma seção sobre história da química, embora o prefácio deixe claro que o foco do livro recai sobre a prática da química, principalmente questões industriais, uma vez que "chemistry has been one of the most powerful factors of progress, civilisation, and improvement in all countries" [a química tem sido um dos mais poderosos fatores de progresso, civilização e crescimento em todos os países], segundo o autor (p. viii). ${ }^{30}$

Esse livro apresenta uma seção, logo em seu início, em que é descrito o "progresso da ciência química" ao longo dos séculos, começando da Antiguidade, abordando China, Egito, Índia, Roma, Grécia, passando pela Idade Média, discorrendo sobre alquimia e iatroquímica, e terminando com a chamada química moderna, citando os trabalhos de Lavoisier e algumas das leis fundamentais dessa ciência (conservação da matéria, lei das proporções constantes, estequiometria, teoria atômica) (p. 9-22). ${ }^{30}$
No livro de Molinari, o conceito de valência é apresentado na primeira parte do livro, dedicada a conceitos gerais da química. A valência é apresentada da seguinte maneira:

Kolbe, by means of his classic studies on the radicals of organic compounds, prepared the ground for Frankland and his fertile and brilliant conception of the theory of valency (1853) (p. 46) [Kolbe, por meio de seus clássicos estudos sobre os radicais dos compostos orgânicos, preparou o terreno para Frankland e sua fértil e brilhante concepção da teoria de valência (1853).] ${ }^{30}$

Com essa afirmação o autor faz uso da história da química de uma forma bem característica da época, ou seja, exaltando grandes cientistas e os feitos da ciência. De qualquer forma, Molinari registra que a valência teve sua origem no âmbito da química orgânica. Depois dessa introdução histórica, o autor define valência como a capacidade de saturação de combinação de um elemento. Molinari a diferencia de afinidade, afirmando que a valência é uma propriedade quantitativa e não qualitativa, sendo determinada por uma fórmula matemática: a razão entre o peso atômico e o peso equivalente no composto estudado. ${ }^{30}$

Por fim, cabe ressaltar que Molinari relaciona a valência de um elemento com a carga do respectivo íon; e relaciona essa carga com a quantidade de elétrons no átomo. $\mathrm{O}$ autor menciona a valência variável como uma característica dos compostos inorgânicos, nos quais os elementos apresentam diferentes graus de saturação e, portanto, possuem uma valência máxima que nem sempre é utilizada em sua totalidade..$^{30}$

\section{Anos 1920}

Foram analisados os seguintes livros desse período: McCoy e Terry (1920), Brownlee (1921), Caven (1921), McPherson e Henderson (1921), Holmes (1922, 1925), Deming (1923, 1925), Foster (1924), Schlesinger (1925), Brinkley (1926), Kendall (1927), McCutcheon e Seltz (1927), Richardson (1927) e Babor (1929). ${ }^{42-56}$ O Quadro 5 sumariza as características observadas nesse conjunto de livros.

Observa-se, nos livros da década de 1920, o início de um processo de transição na abordagem do conceito de valência: no início

Quadro 4. Abordagem do conceito de valência na década de 1910

\begin{tabular}{|c|l|}
\hline Critério & \multicolumn{1}{|c|}{ Década de 1910 } \\
\hline $\begin{array}{c}\text { Localização e frequência } \\
\text { do conceito }\end{array}$ & A maioria aborda a valência em um capítulo ou seção específica no início do livro. \\
\hline Nomenclatura e notação & $\begin{array}{l}\text { Todos usam o termo valence. } \\
\text { Monovalentes ou monádicos, divalentes ou diádicos, etc. } \\
\text { Algarismos romanos ou arábicos; representação por traços que representam a união das valências dos elementos envolvidos. }\end{array}$ \\
\hline Definição & Poder de combinação do elemento ou radical, usando o hidrogênio como unidade. . $^{30-39}$ \\
\hline $\begin{array}{c}\text { Determinaça do valor } \\
\text { da valência }\end{array}$ & $\begin{array}{l}\text { Molinari }{ }^{30} \text { e Hildebrand }{ }^{41} \text { indicam a relação do número de valência com a carga do íon. Os demais determinam a valência } \\
\text { pela análise de fórmulas químicas e pela razão entre o peso atômico e o peso equivalente de cada elemento. }\end{array}$ \\
\hline $\begin{array}{c}\text { História do conceito } \\
\text { Relação com outras teorias }\end{array}$ & $\begin{array}{l}\text { Molinari atribui a Edward Frankland (1825-1899) a teoria de valência e cita alguns trabalhos anteriores relacionados } \\
\text { com a teoria dos tipos e a dos radicais. }{ }^{30} \text { Jones também cita essas teorias e discorre um pouco sobre a química orgânica } \\
\text { de Friedrich August Kekulé (1829-1896). }{ }^{35}\end{array}$ \\
\hline $\begin{array}{l}\text { Exceto Pond, }{ }^{33} \text { McPherson e Henderson }{ }^{36} \text { e Cady, }{ }^{39} \text { todos tratam a valência como uma propriedade dos grupos da tabela } \\
\text { periódica já indicada por Dmitri Mendeleev (1834-1907), e ressaltam que se deve tomar cuidado com as variações que } \\
\text { podem existir, ocorrendo da mesma forma para todos os membros de uma dada família. As variações ocorrem em certos } \\
\text { processos em que as condições e os átomos envolvidos podem interferir na valência, gerando um uso total ou parcial } \\
\text { dessa propriedade, formando assim os compostos saturados ou insaturados, respectivamente. }\end{array}$ \\
\hline Usos e aplicações & $\begin{array}{l}\text { Todos usam a valência para escrever fórmulas e equações químicas, e alguns a usam para definir carga de íons e a no- } \\
\text { menclatura dos compostos. A maioria apresenta uma tabela com os principais valores de valência que devem ser usados. }\end{array}$ \\
\hline
\end{tabular}


Quadro 5. Abordagem do conceito de valência na década de 1920

\begin{tabular}{|c|c|}
\hline Critério & Década de 1920 \\
\hline $\begin{array}{l}\text { Localização e frequência } \\
\text { do conceito }\end{array}$ & $\begin{array}{l}\text { Todos trazem o conceito de valência nos capítulos iniciais: alguns em capítulos específicos, mas a maioria em seções } \\
\text { de capítulos introdutórios, que também apresentam conteúdos sobre fórmulas químicas e nomenclatura de compostos. }\end{array}$ \\
\hline Nomenclatura e notação & $\begin{array}{l}\text { Monovalentes, divalentes, etc. } \\
\text { Algarismos romanos ou arábicos; representação por traços nas chamadas fórmulas estruturais. }\end{array}$ \\
\hline Definição & $\begin{array}{l}\text { Momento de transição: alguns definem a valência como poder de combinação, ou como o número de átomos de hidrogênio } \\
\text { substituídos ou combinados com o elemento em estudo; }{ }^{42-48,52,53,55} \text { outros já a definem como o número de elétrons na camada } \\
\text { mais externa dos átomos. }{ }^{49,56} \text { Alguns a definem das duas formas: a primeira, mais clássica, relacionada às questões de } \\
\text { formulação química; e a segunda, mais moderna, relacionada aos novos modelos eletrônicos. }{ }^{50,51,54}\end{array}$ \\
\hline $\begin{array}{l}\text { Determinação do valor } \\
\text { da valência }\end{array}$ & $\begin{array}{l}\text { Depende da definição apresentada: alguns determinam o valor por meio da razão entre peso atômico e peso equivalente, } \\
\text { outros pela análise de fórmulas, outros fazendo referência a experimentos, e outros, ainda, pela distribuição eletrônica } \\
\text { do elemento. }\end{array}$ \\
\hline História do conceito & $\begin{array}{l}\text { Richardson }{ }^{55} \text { atribui a Frankland a autoria da teoria de valência, que teria sido produzida para facilitar a escrita de fórmulas } \\
\text { químicas. Caven traz um breve relato dos trabalhos de Frankland e Kekulé, citando a controvérsia a respeito do número } \\
\text { de valência ser um valor fixo ou variável para um dado elemento; trata de química orgânica no contexto da valência, ao } \\
\text { citar os trabalhos de Kekulé para a determinação de fórmulas estruturais, mencionando a existência de ligações múltiplas } \\
\text { e a posição de Kekulé em favor da valência constante. }{ }^{44}\end{array}$ \\
\hline Relação com outras teorias & $\begin{array}{l}\text { No início da década, não apresentam a teoria da ligação, ou usam o termo "ligação" como sinônimo de valência nas } \\
\text { fórmulas estruturais. }{ }^{42-50,52} \text { No final da década, apresentam a distribuição eletrônica e discutem a ligação em termos de } \\
\text { combinação de elétrons da última camada; porém, alguns não usam o termo "ligação", apenas "combinação" ou "união" } \\
\text { de elementos. }{ }^{51,53-56} \text { Todos ressaltam a questão da variação da valência de um elemento; no final da década, aparecem como } \\
\text { exemplos os processos de oxidação-redução, nos quais há transferência de elétrons e, portanto, alteração do número de } \\
\text { valência. Exceto Deming, }{ }^{49} \text { todos trazem a valência como uma propriedade periódica, que ajuda a definir o número dos } \\
\text { grupos da tabela periódica. A maioria traz as fórmulas de óxidos e hidretos para mostrar a periodicidade e para discutir o } \\
\text { caráter positivo ou negativo do número de valência. Ressaltam que se deve usar o valor mais alto e mais comum no caso } \\
\text { dos elementos com mais de uma valência. No final da década, já trazem a distribuição eletrônica como outra propriedade } \\
\text { periódica relacionada à valência. }\end{array}$ \\
\hline Usos e aplicações & $\begin{array}{l}\text { Escrita de fórmulas e equações químicas. O principal tipo de reação química para o qual se utiliza a valência para a escrita } \\
\text { das equações é a chamada oxidação-redução. }\end{array}$ \\
\hline
\end{tabular}

da década, os livros ainda o definem apenas da maneira clássica, como poder de combinação. A partir de meados da década, surge a definição em termos de número de elétrons na camada mais externa dos átomos, e alguns livros passam a incluir a nova definição eletrônica ao lado da definição clássica. A introdução das novas teorias sobre estrutura eletrônica nos livros didáticos modifica também a abordagem para a tabela periódica: no final da década, os livros já incluem a distribuição eletrônica como outra propriedade periódica, relacionada com a valência. ${ }^{42-48,50-56} \mathrm{~A}$ ligação entre átomos, até então descrita nos livros como consequência das valências, começa a ser discutida em termos de combinação de elétrons de valência, ou seja, dos elétrons da última camada dos átomos.

Desse período, foi analisado em maior profundidade o livro de Caven, por apresentar um pouco da história do conceito de valência e por ser o único autor do período a abordar a química orgânica no contexto da valência. Além disso, o autor deixa claro no prefácio que o objetivo do livro é mostrar fatos da ciência química de uma forma compreensível e agradável ao estudante, para que ele passe a apreciar essa área, o que faz com que o livro não seja tão focado nos conteúdos e traga essas discussões sobre história e aplicação da ciência de uma forma acessível aos iniciantes. ${ }^{44}$

Nessa obra, o conceito de valência é abordado em vários momentos do livro com diferentes enfoques, como era comum na época. A primeira menção ao conceito ocorre no capítulo 2, dedicado aos pesos atômicos e moleculares, no qual a valência é definida matematicamente como a razão entre o peso atômico e o peso equivalente de um elemento em determinado composto, ou seja, é um valor numérico. O capítulo 3 é dedicado à valência (grafada como valency), e nele Caven retoma a história, citando Frankland e Kekulé. Frankland é descrito como o cientista que mostrou e definiu o que era o poder de combinação dos elementos e sua capacidade de saturação ao formar compostos, e Kekulé é citado como o cientista que desenvolveu a química orgânica e estudou profundamente o carbono e seus compostos. Nesse capítulo, a valência é definida como um número que indica a quantidade de átomos com os quais um elemento pode se combinar. A partir dessa definição, Caven classifica os elementos e traz vários exemplos, incluindo as fórmulas gráficas, criadas por Archibald Couper (1831-1892) para representar as unidades de valência que unem os átomos. ${ }^{44}$

Outro aspecto interessante da obra de Caven é a discussão sobre a variação da valência. $\mathrm{O}$ autor apresenta as controvérsias da época de construção do conceito e os argumentos dos diferentes grupos de cientistas. Caven explica que Kekulé defendia a constância da valência com base em seus estudos sobre os compostos de carbono e sua teoria das ligações múltiplas entre os átomos, e mostra que Frankland defendia a variação da valência com base em seus estudos com os compostos de nitrogênio e sua classificação em saturados ou insaturados conforme o uso total ou parcial da valência. Caven também ressalta, alguns capítulos adiante, que, apesar dessa discussão e de alguns elementos possuírem mais de uma valência, essa propriedade foi utilizada como um dos critérios para a construção da tabela periódica, sendo que o número de cada grupo da tabela está relacionado diretamente ao número de valência mais comum para os elementos que o integram. ${ }^{44}$

Por fim, cabe mencionar que Caven retoma a valência em mais três momentos no livro, como ao relacioná-lo com a carga do íon formado por um dado elemento. Em outro momento, ao final do capítulo dedicado à valência, o autor discute brevemente sua natureza eletrônica, relacionando a valência com a perda ou ganho de elétrons por um elemento. Caven cita diversos autores, como Humphry Davy (1778 - 1829), Jöns Jacob Berzelius (1779-1848), Michael Faraday (1791-1867) e William Crookes (1832-1919), que 
contribuíram para o desenvolvimento de ideias que relacionavam a eletricidade com a composição das substâncias, para enfim apontar J. J. Thomson (1856-1940) e William Ramsay (1852-1916) como elaboradores de uma teoria que relacionou a valência aos elétrons. Finalmente, Caven retoma o conceito de valência no estudo das reações de oxidação-redução, e o utiliza para explicar o processo e balancear as equações que o representam (sem fazer menção a elétrons, apenas considerando oxidação e redução como, em geral, aumento ou diminuição da valência). ${ }^{44}$

\section{Anos 1930}

Foram analisados os seguintes livros desse período: Hopkins (1930), Foster (1931), Brinkley (1932), Timm (1932), Belcher e Williams (1934), Bond (1935), Briscoe (1935), Dunbar (1939), Irwin e Sherwood (1939) e Sears (1939). ${ }^{57-66}$ O Quadro 6 sumariza as características observadas nesse conjunto de livros.

A transição iniciada na década anterior prossegue nos anos 1930: os livros didáticos definem a valência como poder de combinação e como número de elétrons na última camada do átomo, ou como a carga do íon mais estável. A determinação do valor da valência é feita pela análise das fórmulas dos compostos e, também, pela distribuição eletrônica. A valência é relacionada diretamente com a tabela periódica, por meio da distribuição eletrônica, e, também, com os tipos de ligação química (então chamados de eletrovalência e covalência).

Desse período, analisamos mais detidamente o livro de Timm, ${ }^{60}$ que se destaca pelo posicionamento do autor em defesa de uma mudança no ensino da química - a qual seria necessária em decorrência dos desenvolvimentos recentes dessa ciência. Timm argumenta em favor de uma abordagem mais filosófica, cujo foco recaia sobre o desenvolvimento das teorias, diminuindo, por outro lado, discussões matemáticas muito aprofundadas. Segundo o autor, seria mais importante ensinar como a ciência funciona, seus procedimentos e aplicações. Isso dá margem a um maior uso da história da ciência, o que é verificado em capítulos iniciais, nos quais a abordagem histórica é usada para construir conceitos a partir de ideias e definições anteriores. Essa abordagem é usada também para o conceito de valência, o qual é apresentado na seção 7 do capítulo 8 (intitulado "A taquigrafia da química", e que traz conceitos como símbolos químicos, fórmulas, equações químicas, etc.). Nesse capítulo, Timm inicia com a definição clássica de poder de combinação, a qual foi proposta pelo estudo da composição de diversas substâncias. Nessa parte, a valência é representada por números romanos, e seus valores são sistematizados numa tabela na qual os elementos são classificados por sua valência mais comum. Em seções subsequentes, o autor passa a relacionar a

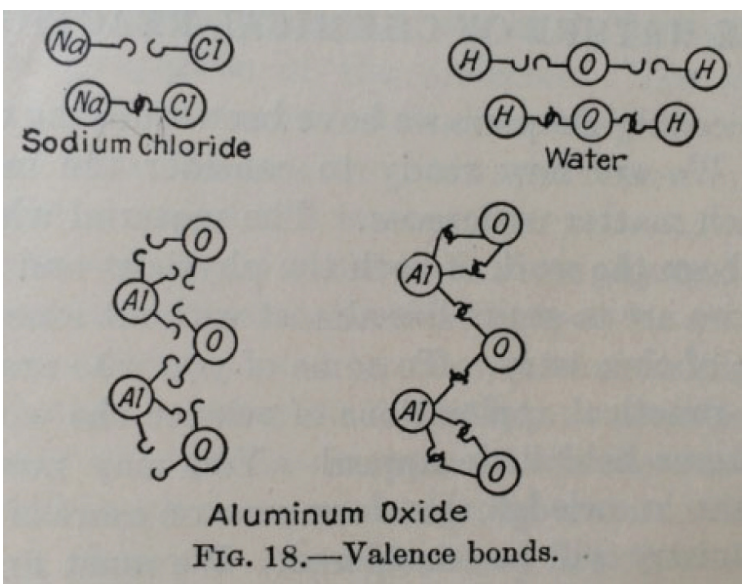

Figura 1. Representação das valências como ganchos, e das chamadas "ligações de valência” como engates entre os ganchos (reproduzido da ref. 60, p. 89)

Quadro 6. Abordagem do conceito de valência na década de 1930

\begin{tabular}{|c|c|}
\hline Critério & Década de 1930 \\
\hline $\begin{array}{l}\text { Localização e frequência } \\
\text { do conceito }\end{array}$ & $\begin{array}{l}\text { Todos trazem a valência no início, em capítulos dedicados aos princípios fundamentais, à tabela periódica, ou à nomen- } \\
\text { clatura química. }\end{array}$ \\
\hline Nomenclatura e notação & $\begin{array}{l}\text { Monovalentes, divalentes, etc. } \\
\text { Números romanos ou arábicos com sinal (que indica o caráter eletropositivo ou negativo do elemento), ou traços nas } \\
\text { fórmulas estruturais. }\end{array}$ \\
\hline Definição & $\begin{array}{l}\text { Transição: todos trazem duas definições, às vezes em lugares distintos do livro: inicialmente, definem a valência como } \\
\text { poder de combinação e, mais adiante, como o número de elétrons na camada mais externa do átomo, ou como a carga } \\
\text { do íon formado pelo átomo. }\end{array}$ \\
\hline $\begin{array}{l}\text { Determinação do valor } \\
\text { da valência }\end{array}$ & $\begin{array}{l}\text { Transição entre o clássico (determinação pela proporcionalidade de massas em experimentos - por exemplo, reação de } \\
\text { ácido com metal - ou pela razão entre o peso atômico e o peso equivalente) e o moderno ou eletrônico (determinação } \\
\text { pela distribuição eletrônica do elemento). }\end{array}$ \\
\hline História do conceito & Não aparece. \\
\hline Relação com outras teorias & $\begin{array}{l}\text { Timm é o único que inclui um capítulo relacionando o conceito de valência com a química orgânica: a valência aparece } \\
\text { na discussão sobre compostos saturados e insaturados e sobre ligações múltiplas. }{ }^{60} \text { Todos trazem a valência como uma } \\
\text { propriedade periódica. Belcher e Williams trazem também a distribuição eletrônica como propriedade periódica rela- } \\
\text { cionada com a valência. }{ }^{61} \text { Alguns ressaltam que todos os elementos de um dado grupo da tabela periódica apresentam o } \\
\text { mesmo número de valência - havendo, porém, exceções, às quais se deve estar atento. }{ }^{58,60,63} \text { Todos mostram a existência } \\
\text { de elementos com mais de uma valência, principalmente entre os metais de transição, fenômeno atribuído à presença de } \\
\text { camadas internas com mais elétrons. A explicação é que a variação na valência pode ocorrer dependendo das condições } \\
\text { ambientais e dos átomos envolvidos, nas reações chamadas de oxidação-redução. Apresenta-se uma relação direta entre a } \\
\text { ligação química e a valência: os elétrons da última camada são usados para as combinações entre os elementos, formando } \\
\text { as ligações químicas. Os livros trazem duas classificações para a valência e para a ligação: eletrovalência (união de dois } \\
\text { ou mais elementos químicos distintos pela transferência de elétrons) e covalência (união entre dois ou mais elementos } \\
\text { químicos iguais ou diferentes pelo compartilhamento de elétrons). Na covalência, a ligação pode ser apolar, se for consti- } \\
\text { tuída por apenas um elemento químico, ou polar, se for constituída por mais de um elemento químico. (A eletrovalência } \\
\text { é hoje chamada de ligação iônica, e a covalência, de ligação covalente.) }\end{array}$ \\
\hline Usos e aplicações & $\begin{array}{l}\text { Além da escrita de fórmulas e equações químicas, a valência é usada também para balanceamento de equações de oxidação- } \\
\text { redução e para classificar as ligações químicas entre os elementos. }\end{array}$ \\
\hline
\end{tabular}


valência com a ligação química. Timm introduz uma ilustração na qual os átomos são dotados de ganchos (um gancho para cada uma de suas valências), cujo engate é substituído, nas representações que aparecem na sequência, pelos traços das fórmulas estruturais. ${ }^{60}$

A respeito dessa ilustração, Timm escreveu:

It must not for a moment be supposed that atoms are actually linked together by any such physical hooks or bonds as we have just discussed. Such linkages give only a convenient thought model of the structural frame work of a molecule. Until recently scientists had no clear picture of the nature of these bonds. With an increasing knowledge of atomic structure there has come a theory of the nature of valence which is of the greatest interest and significance. This theory will be discussed in a later chapter. (p. 89) [Não se deve, sequer por um momento, supor que os átomos estão realmente ligados por quaisquer ganchos físicos ou ligações, como as que acabamos de discutir. Tais ligações fornecem somente um modelo mental conveniente do arcabouço estrutural de uma molécula. Até recentemente, os cientistas não tinham uma imagem clara a respeito da natureza dessas ligações. Com o crescente conhecimento da estrutura atômica, surgiu uma teoria da natureza da valência que é do maior interesse e importância. Essa teoria será discutida em um capítulo posterior. $]^{60}$

Mais adiante no livro, a valência é retomada como uma propriedade periódica (capítulo 16), e ressignificada com a definição eletrônica (capítulo 18). Timm então apresenta a valência como a quantidade de elétrons da última camada eletrônica de um átomo, mas ressalva que há processos que envolvem perda e ganho de elétrons, os quais alteram o valor dessa propriedade nos produtos das reações. Além disso, há compostos nos quais elétrons de camadas mais internas também podem ser utilizados, o que também leva a uma alteração no número de valência do elemento.

Além de trazer essa nova definição, Timm aborda as reações de oxidação-redução de forma aprofundada, e sumariza o que ele chama de "natureza da valência". Esse resumo se assemelha muito às regras de utilização dos números de oxidação, utilizados no ensino de química na atualidade, e inclui os seguintes pontos: valência é igual à carga elétrica do átomo; valência é igual a zero para elementos não combinados; valência é positiva para metais e negativa para ametais, com exceção de ametais ligados a oxigênio, que possuem valência positiva; a variação da valência está ligada ao número de elétrons perdidos ou recebidos no processo; e a soma dos números de valência é nula para compostos, ou igual à carga para íons. Essa relação com a carga do íon é retomada nos capítulos específicos sobre dissociação eletrolítica e eletrólitos (capítulos 26 e 27). ${ }^{60}$

\section{Anos 1940}

Foram analisados os seguintes livros desse período: Babor e Lehrman (1940), Richardson e Scarlett (1940), Young e Porter (1940), Brinkley (1941), MIT (1943), Deming (1944), Sneed (1944), Partington (1966; $1^{\text {a }}$. ed., 1946), Pauling (1947), Currier e Rose (1948), Laubengayer (1949) e Sisler, Van der Werf e Davidson (1949). ${ }^{67-78}$ O Quadro 7 sumariza as características observadas nesse conjunto de livros.

Observa-se, nos livros da década de 1940, a continuidade do processo de proposição de novos termos que decorrem de diferenciações e elaborações a partir do conceito de valência - como visto na década anterior, com o uso dos termos eletrovalência e covalência. Pauling propõe o termo valência iônica ${ }^{74}$ e aparece, pela primeira vez entre os livros analisados, o termo número de oxidação. É clara a relação entre essa nova expressão e a antiga questão da valência ser variável para um dado elemento químico. Assim, o número de

Quadro 7. Abordagem do conceito de valência na década de 1940

\begin{tabular}{|c|c|}
\hline Critério & Década de 1940 \\
\hline $\begin{array}{l}\text { Localização e frequência do } \\
\text { conceito }\end{array}$ & Todos trazem a valência no início e, muitas vezes, em mais de um capítulo. \\
\hline Nomenclatura e notação & $\begin{array}{l}\text { Monovalentes, divalentes, etc. } \\
\text { Números positivos ou negativos, ou traços que seriam as ligações de valência nas fórmulas estruturais. }\end{array}$ \\
\hline Definição & $\begin{array}{l}\text { Todos definem como poder de combinação, determinado pelo número de átomos de hidrogênio com que o elemento se } \\
\text { une ou que substitui; ou pela razão entre o peso atômico e o peso equivalente; ou, ainda, pelo número de elétrons na } \\
\text { camada de valência. }\end{array}$ \\
\hline $\begin{array}{l}\text { Determinação do valor da } \\
\text { valência }\end{array}$ & Pela análise de fórmulas químicas, ou como resultado de experimentos; ou pela distribuição eletrônica. \\
\hline História do conceito & $\begin{array}{l}\text { Richardson e Scarlett apenas citam Frankland como o criador do termo valence }{ }^{68} \text { Sneed atribui a autoria da notação por } \\
\text { traços a William Odling }(1829-1921) ;{ }^{73} \text { e Pauling atribui a autoria da teoria de valência a Frankland, da teoria da ligação } \\
\text { química a Couper e das cadeias de carbono a Kekulé. }{ }^{74} \text { Partington apresenta mais detalhes e cita mais autores relacionados } \\
\text { à construção do conceito de valência. }{ }^{78}\end{array}$ \\
\hline Relação com outras teorias & $\begin{array}{l}\text { Todos indicam ou a valência ou a distribuição eletrônica como propriedades periódicas. Muitos ressaltam a importância } \\
\text { de se colocar o sinal positivo na valência quando o elemento em questão forma óxido, e o sinal negativo quando forma } \\
\text { hidreto. Pauling apresenta, como propriedade periódica, a valência iônica, que seria a carga do íon, ou seja, a valência } \\
\text { precedida do sinal positivo ou negativo, o que Laubengayer chama de número de oxidação. }{ }^{74} \text { Todos tratam a ligação } \\
\text { química em termos de ganho e perda ou compartilhamento de elétrons, sendo a primeira chamada de eletrovalência ou } \\
\text { valência iônica (esta nomenclatura é usada apenas por Pauling), e a segunda de covalência. A movimentação de elétrons } \\
\text { pode ocorrer entre os elementos em um composto, ou em uma reação química entre compostos. Nestes processos de } \\
\text { oxidação-redução há variação do número de valência, que passa a ser chamado de número de oxidação, ficando o termo } \\
\text { "número de valência" para o maior ou o mais comum número de oxidação que o elemento pode exibir. Essa diferenciação } \\
\text { é meramente formal, e foi criada para evitar confusões: o número de valência é fixo para um dado elemento, e o número } \\
\text { que varia conforme a movimentação dos elétrons foi chamado de número de oxidação. }\end{array}$ \\
\hline Usos e aplicações & $\begin{array}{l}\text { Escrever fórmulas, ligações e equações químicas. Para o balanceamento das equações de oxidação-redução os autores } \\
\text { utilizam o número de oxidação. }\end{array}$ \\
\hline
\end{tabular}


oxidação passa a designar as diferentes "valências" possíveis de um elemento, enquanto o termo valência passa a ser atribuído apenas ao valor máximo ou mais comum observado para um dado elemento.

Desse período, foram analisados com maior profundidade três livros: Deming ${ }^{72}$ por ser um autor recorrente no início do século XX, tendo publicado várias edições de seus livros didáticos; Pauling, ${ }^{74}$ pela influência de seu autor, tanto no campo da química como no ensino dessa ciência, e particularmente pelo fato da obra selecionada apresentar questões históricas e proposições para se alterar o ensino do conceito de valência; e Partington, ${ }^{78}$ pelo fato de o autor haver se notabilizado como historiador da química.

Em relação ao livro de Deming, cabe ressaltar que há um grande enfoque em aplicações práticas do conhecimento químico na indústria, o que, segundo o autor, estava ligado ao esforço de guerra dos EUA. Além disso, é um livro cujo objetivo, anunciado no prefácio, era ser flexível, dando ao professor e ao aluno liberdade para estudar os capítulos que fossem mais convenientes, na ordem que achassem melhor. Dessa forma, os capítulos são independentes, e retomam alguns conteúdos trabalhados anteriormente de forma sucinta. ${ }^{72}$

Nessa obra, o conceito de valência é introduzido pela primeira vez no capítulo 11, dedicado aos elementos, no qual é apresentada e discutida a tabela periódica, sendo a valência incluída como uma das propriedades periódicas. O valor da valência de um elemento é apresentado como sendo numericamente igual ao número do grupo ao qual o elemento pertence. A valência é definida como a quantidade de átomos de hidrogênio com a qual o átomo de um determinado elemento se combina ou desloca em uma reação química, podendo, em alguns casos, assumir mais de um valor, porém não há explicação para tal fato nesse ponto. Mais adiante no livro, o autor afirma que as propriedades periódicas, e a própria tabela periódica, estão relacionadas com a distribuição eletrônica nos átomos. Pode-se inferir que, como a valência se inclui entre essas propriedades, ela também estaria relacionada com os elétrons. ${ }^{72}$

O livro de Deming retoma a valência em outros dois pontos: ao definir os tipos de valência, relacionando-os com os tipos de ligação química, uma vez que ambas as classificações utilizam os mesmos nomes, iônica e covalente; e na discussão sobre reações de oxidação-redução, as quais são explicadas pelo ganho ou perda de elétrons, que seria equivalente a diminuição ou aumento do número de valência do elemento. Além desses pontos, cabe ressaltar que o conceito de valência aparece em locais diversos do livro, sendo descrito como uma das propriedades dos elementos químicos apresentados, usado para escrever fórmulas e para prever produtos de reações químicas. ${ }^{72}$

No livro de Pauling, um dos aspectos mais relevantes em relação ao conceito de valência é a ressalva que o autor faz a respeito do uso indiscriminado do termo valence. Após defini-lo de forma clássica como poder de combinação de um elemento, e discorrer sobre fórmulas químicas e ligações de valência, Pauling adverte:

The concept of valence as discussed above is not rigorously defined, and many puzzling questions may present themselves (...) The effort to obtain a clear understanding of the nature of valence and of chemical combination in general has led in recent years to the dissociation of the concept of valence into several new concepts - of ionic valence, oxidation number, covalence, coordination number - corresponding to the different modes of interaction of the atoms (...) Some chemists have felt that the word valence might well be allowed to drop into disuse, in favor of these more precise terms. In practice, however, valence continues to be used as a general expression of the combining powers of the elements or as a synonym for one or another of the more precise terms (p. 119-120) [O conceito de valência, como discutido acima, não está rigorosamente definido, e muitas questões desafiadoras podem se apresentar (...). O esforço para obter um claro entendimento da natureza da valência e da combinação química em geral levou, nos últimos anos, à dissociação do conceito de valência em vários novos conceitos - valência iônica, número de oxidação, covalência, número de coordenação - correspondendo aos diferentes modos de interação entre os átomos. (...) Alguns químicos acharam que a palavra valência poderia muito bem cair em desuso, em favor desses termos mais precisos. Na prática, entretanto, a valência continua a ser usada como uma expressão geral do poder de combinação dos elementos, ou como sinônimo para um ou outro dos termos mais precisos. $]^{74}$

Seguindo essa linha de pensamento, Pauling então discute cada um dos termos e aspectos relacionados ao conceito de valência, fazendo uso dos outros termos citados acima. $\mathrm{O}$ autor aborda a proporção entre os elementos nos óxidos, quando discute as propriedades periódicas. Discute os tipos de ligação química - iônica, covalente e coordenada - em termos eletrônicos, ou seja, como doação de elétrons, compartilhamento de elétrons e doação com compartilhamento de elétrons, respectivamente. Pauling usa as fórmulas de Lewis para montar as moléculas e em seguida as representa usando as fórmulas estruturais, a partir das quais discute geometria, polaridade e outras propriedades moleculares. Também discute os processos de oxidação-redução em termos da variação do número de oxidação, sendo explicados pela transferência de elétrons entre os elementos. ${ }^{74}$

Ao final da discussão dos termos mais específicos, Pauling apresenta uma seção chamada "Desenvolvimento da Teoria Eletrônica de Valência", na qual faz um pequeno resumo da história dessa teoria. Começa mencionando os estudos que levaram à teoria dualística no início do século XIX proposta por Berzelius, e os problemas surgidos com o advento da química orgânica, cujos compostos não se encaixavam naquela teoria. Na sequência, Pauling cita os trabalhos de Frankland que, em 1852, afirmou que os átomos tinham um poder de combinação definido, o qual determina as fórmulas dos compostos. Também são citados Couper, que em 1858 teria escrito as primeiras fórmulas estruturais, e Kekulé, que também em 1858 realizou diversos estudos sobre o carbono e desenvolveu a teoria da química orgânica com base nas cadeias de carbono. Ainda no século XIX, Pauling menciona as contribuições de Jacobus Henricus Van't Hoff (1852-1911) e Joseph Le Bel (1847-1930) sobre a geometria dos compostos orgânicos. Ao final desse apanhado histórico, o autor focaliza ideias desenvolvidas no século XX, citando os trabalhos de Gilbert Lewis (1875-1946) que, em 1916, explicou a valência com base nos elétrons. Pauling conclui essa seção afirmando que, naquele momento (anos 1940) estavam sendo realizados diversos estudos sobre a estrutura das moléculas utilizando a química quântica. Essa discussão histórica, embora se possa dizer que é mais completa que a de outros livros do período, é feita de forma bem resumida, e está colocada após a apresentação do conceito de valência e de seus usos. Isso pode fazer com que a discussão histórica seja encarada como tendo um caráter complementar ou meramente informativo, não sendo essencial e estando isolada da discussão conceitual anterior. ${ }^{74}$

Em relação a Partington, seu viés de historiador da química transparece no fato de dedicar a introdução de seu livro à história da química, incluindo uma seção sobre a história do conceito de valência, na qual são abordadas a teoria unitária, a teoria dos tipos e a teoria dos radicais, sendo citados vários químicos [Frankland, Adolph Kolbe (1818-1884), Robert Bunsen (1811-1899), Jean-Baptiste Dumas (1800-1884), Charles Gerhardt (1816-1856)]. Partington atribui a Frankland a teoria de valência e a Couper a representação por traços. Também é abordada a discussão entre Frankland e Kekulé sobre a variação da valência. Essa parte do texto termina relacionando o 
dualismo e a nova teoria eletrônica, mencionando a teoria da ligação de valência, atribuída a Lewis. Essa discussão é retomada e resumida nos primeiros parágrafos do capítulo 10 , dedicado à teoria quântica, o que demonstra a importância atribuída ao conceito de valência pelo autor. ${ }^{78}$ De acordo com Partington:

Since its enunciation by Frankland in 1852 the idea of valency has been a guiding star in chemical research. The elementary conception of the saturation capacity of atoms, and the use of structural formulae in which bonds replace numerical valencies, have served chemists well over a long period of years (...) $[\mathrm{R}]$ esearch added quantitative data in the shape of atomic and molecular dimensions, bond angles, and a clearer idea of the different types of linkage (...) Chemists have naturally speculated freely on the nature of valency, and since the discovery of the electron in 1897 many "electronic theories of valency" were proposed, culminating in the electron-pair theory of G. N. Lewis (1916), which still possesses vitality and promise (p. 255, grifo no original). [Desde sua enunciação por Frankland em 1852, a ideia de valência tem sido uma estrela guia na pesquisa em química. A concepção elementar da capacidade de saturação dos átomos e o uso de fórmulas estruturais, nas quais as ligações substituem os valores numéricos das valências, têm servido bem aos químicos por um longo período de tempo (...) Pesquisas adicionaram dados quantitativos às formas de dimensões atômicas e moleculares, aos ângulos de ligação, e uma ideia mais clara dos tipos de ligação (...). Os químicos têm especulado natural e livremente sobre a natureza da valência, e desde a descoberta do elétron, em 1897, muitas "teorias eletrônicas de valência" foram propostas, culminando na teoria do par eletrônico de G. N. Lewis (1916), que ainda possui vitalidade e é promissora. $]^{78}$

Seguindo o enfoque histórico da introdução, o livro apresenta primeiramente a definição clássica de valência como poder de combinação, em termos do número de átomos de hidrogênio com o qual um dado elemento pode se combinar. Ao discutir a tabela periódica, no capítulo 7, o autor explica que: "The arrangement of the elements, or of groups of elements, in the order of their atomic weights, corresponds with their so-called valencies" (p. 174) [O arranjo dos elementos, ou dos grupos de elementos, na ordem de seus pesos atômicos tem correspondência com suas assim chamadas valências]. ${ }^{78}$

A definição eletrônica é apresentada posteriormente, no capítulo 8, no qual, após discutir a estrutura atômica, Partington passa a relacionar a valência com os elétrons da última camada. Partington define os tipos de valência, também chamados pelo autor de tipos de ligação química (eletrovalência, covalência e coordenação), usando nessa parte as fórmulas de Lewis junto com a notação por traços. Partington retoma a valência e a ligação química no capítulo 10 , sobre teoria quântica, discutindo ambos os conceitos em termos de orbitais, funções de ondas e spins eletrônicos. ${ }^{78}$

\section{CONSIDERAÇÕES FINAIS}

Ao comparar as abordagens dos livros didáticos ao longo das décadas, buscou-se identificar estratégias didáticas para o ensino do conceito de valência, observando-se modificações e permanências na forma de apresentá-lo. No início do século XX, a valência era apresentada como um conceito empírico, e os autores recorriam a ele especialmente com uma finalidade bastante prática: escrever fórmulas de compostos químicos. Na época, não havia receio em admitir que a origem ou a causa da valência era desconhecida. $\mathrm{O}$ advento de teorias sobre a estrutura eletrônica dos átomos levou a mudanças nessa abordagem. Observou-se a existência de um período de transição entre o conceito clássico e o conceito eletrônico, que ocorreu entre os anos 1920 e 1930, no qual ambas as definições passaram a ser apresentadas pelos livros, muitas vezes em passagens distintas na mesma obra. Nesse período, que coincide historicamente com o período entre guerras, novas ideias foram aceitas e antigas ideias foram abandonadas. Dois exemplos disso, observados nos livros didáticos analisados, são as abordagens para o conceito de átomo e o conceito de valência, o qual foi abordado no presente artigo. Nas décadas seguintes, passa a haver um gradual predomínio da abordagem eletrônica para a valência. Os modelos explicativos desenvolvidos no período anterior passam a ocupar um lugar central na apresentação didática da química geral, e o conceito de valência passa a ser relacionado a outros, como ligação química e número de oxidação.

A determinação do valor da valência aparece de diferentes formas ao longo dos períodos, sendo mais comum, até os anos 1930, a análise das fórmulas dos compostos, ou seja, uma determinação empírica. A distribuição eletrônica e contagem dos elétrons na última camada se disseminam nos anos subsequentes. Além dessas, também são citadas a determinação por meio da análise dos produtos das reações de metais com ácidos, ou pela razão entre o peso atômico e o peso equivalente, apresentada por alguns livros de forma isolada ou juntamente com as determinações mais comuns. A maioria dos livros apresenta tabelas com os valores de valência que devem ser usados para facilitar o trabalho de escrita de fórmulas, seja no próprio corpo do texto ou em anexos ao fim das obras.

Cabe ressaltar a grande importância que os livros dão para o conceito de ligação química, o qual se modificou ao longo do período estudado. Inicialmente, a ligação química era considerada apenas como a união dos átomos, sendo sinônimo de valência, não havendo discussões sobre sua natureza. Após os anos 1930, com o uso maior da teoria eletrônica, a forma de apresentação é invertida: a valência passa a ter menor importância diante da ligação química, que se torna um conceito mais relevante.

Em relação à nomenclatura, percebe-se que, no período estudado, os livros usam predominantemente o termo valence (em detrimento de valency e de termos antigos, como quantivalence). As notações variaram gradualmente: os algarismos romanos, mais usados no início do período estudado, foram sendo abandonados em favor dos arábicos. Isso ocorreu juntamente com a adoção de sinais de positivo e negativo associados aos valores das valências, tendência que afinal se diferenciou no conceito de número de oxidação. Os traços entre os símbolos dos elementos nas fórmulas estruturais - que, no início, representavam valências - com o tempo passaram a representar ligações químicas. As fórmulas estruturais, em particular, demonstram um aspecto de interesse no contexto das estratégias didáticas utilizadas nos livros investigados. Embora essas formas de representação fossem bastante utilizadas, os livros não discutem em profundidade a teoria estrutural para os compostos no contexto da valência.

A relação do conceito de valência com a tabela periódica aparece em quase todas as obras analisadas, inicialmente em termos empíricos e, posteriormente, com a inserção da explicação de ambas em termos de distribuição eletrônica.

A ausência de maiores considerações sobre a química orgânica na discussão da valência pode ser explicada por uma estratégia didática comum a muitos dos autores - que é fazer o foco principal da química geral recair sobre a química inorgânica. Também o uso da história do conceito de valência foi uma estratégia didática pouco explorada pelos autores cujas obras foram investigadas. Algum aspecto histórico aparece em livros de todos os períodos estudados, com diferentes graus de aprofundamento; mas, em geral, somente se apresentam nomes e atribuições de prioridade de forma superficial e sem discutir o processo de desenvolvimento do conceito de valência. 
Da década de 1950 em diante, consolida-se a abordagem eletrônica para a valência. A distribuição eletrônica é apresentada como uma propriedade periódica dos elementos, e a valência é vista como decorrência dela. Alguns livros didáticos passam a apresentar o número de oxidação como uma propriedade periódica, ou seja, o número de valência com sinal positivo ou negativo, indicando a carga elétrica. Discute-se a variação da valência em termos de variação do número de oxidação pela transferência de elétrons, caracterizando os processos de oxidação-redução, com o envolvimento dos elétrons mais internos no caso dos metais de transição. Os conceitos surgidos nas décadas precedentes (número de oxidação, tipos de ligações químicas, transferência de elétrons), relacionados à antiga ideia de valência, não ficam restritos aos capítulos iniciais, mas disseminam-se por vários capítulos dos livros. Porém, ao contrário do que, segundo Pauling, muitos esperavam, o termo valência não caiu em desuso. ${ }^{74} \mathrm{~A}$ valência continuou a ser usada, durante a década de 1950 e adiante, para escrever fórmulas e equações químicas. Para o balanceamento das equações de oxidação-redução, consolidou-se o uso dos números de oxidação.

Uma característica cuja transformação foi possível observar nos livros didáticos do período estudado diz respeito às certezas e incertezas referentes ao conhecimento. Nas décadas iniciais do século XX, os autores de livros didáticos de química reconhecem explicitamente algumas lacunas no conhecimento, como a falta de explicações para a natureza da valência ou para a variação periódica das propriedades dos elementos. Com o passar do tempo, essas lacunas vão sendo preenchidas, os livros didáticos vão se livrando das incertezas, e seus autores expressam confiança de que as teorias correntes seriam capazes de explicar toda a química - uma tendência que parece se estender até os dias atuais.

\section{AGRADECIMENTOS}

Os autores agradecem à Fundação de Amparo à Pesquisa do Estado de São Paulo (FAPESP) pela concessão de bolsas de mestrado (2016/09213-5) e de pesquisa no exterior (2014/24213-6), ao Conselho Nacional de Desenvolvimento Científico e Tecnológico (CNPq) pelo auxílio à pesquisa (426519/2016) e pela concessão de bolsa de produtividade em pesquisa (307652/2017-3).

\section{REFERENCIAS}

1. Kuhn, T. S.; A Estrutura das Revoluções Científicas. Perspectiva: São Paulo, 2009.

2. Campos, C.; Cachapuz, A.; Quim. Nova Esc. 2010, 32, 107.

3. Coracini, M. J.; Interpretação, autoria e legitimação do livro didático, Pontes: São Paulo, 1999.

4. Campanario, J. M.; Enseñanza de las ciencias 2001, 19, 351.

5. Bensaude-Vincent, B.; Sci. Educ. 2006, 15, 667.

6. Souza, K. A. F. D.; Mate, C. H.; Porto, P. A.; Ciência \& Educação 2011, $17,679$.

7. Choppin, A.; Educação e Pesquisa 2004, 30, 549.

8. Olesko, K. M.; Sci. Educ. 2006, 15, 863.

9. Niaz, M. A.; Instructional Science 2000, 28, 23.

10. Fernandes, M. A. M.; Porto, P. A.; Quim. Nova 2012, 35, 420.

11. Leite, H. S. A.; Porto, P. A.; Quim. Nova 2015, 38, 580.

12. https://doi.org/10.1351/goldbook.V06588, acessada em novembro de 2018.

13. Araújo Neto, W. N.; Cad. Temáticos Quim. Nova Esc. 2007, 7, 13.

14. Pimentel, A.; Cadernos de Pesquisa 2001, 114, 179.

15. Moraes, R.; Galiazzi, M. C.; Ciência \& Educação 2006, 12, 117.

16. Russell, C. A.; History of valency. University of Chicago Press: Chicago, 1971.
17. Attfield, J.; Chemistry: general, medical, and pharmaceutical, including the chemistry of the U.S. Pharmacopoia; a manual on the general principles of the science, and their applications in medicine and pharmacy, $14^{\text {th }}$ ed., Lea Brothers \& Co.: Philadelphia, 1894.

18. Freer, P. C.; Descriptive inorganic general chemistry - A text book for colleges, Edição revisada, Allyn and Bacon: Boston, 1894.

19. Sadtler, S. P.; Trimble, H. A text-book of chemistry, intended for the use of pharmaceutical and medical students. Lippincott: Philadelphia, 1895.

20. Ostwald, W.; Outlines of general chemistry, Walker, J., trad.; $2^{\text {nd }}$ ed., Macmillan: London, 1895.

21. Long, J. H.; Elements of general chemistry, with experiments. E. H. Colegrove: Chicago, 1898.

22. Fetterolf, D. W.; 300 questions and answers on general chemistry: The answers given in these notes are adapted from the text-books of recognized authorities, Privately printed: Philadelphia, 1900.

23. Tillman, S. E.; Descriptive general chemistry - a text-book for short course, $3^{\text {rd }}$ ed. rev., J. Wiley: New York, 1904.

24. McPherson, W.; Henderson, W. E. An elementary study of chemistry. Ginn \& Company: Boston, 1906.

25. Pond, G. G.; An outline of a course of instruction in general chemistry, $5^{\text {th }}$ ed., Lippincott: Philadelphia, 1906.

26. Brownlee, R. B.; First Principles of Chemistry, Allyn and Bacon: Boston, 1907.

27. Smith, A.; General chemistry for colleges. Century: New York, 1908.

28. Baskerville, C.; General inorganic chemistry, D. C. Heath \& Co.: Boston, 1909.

29. Ostwald, W. Outlines of general chemistry, Taylor, W. W., trad.; $3^{\text {rd. }}$ ed., Macmillan and Co.: London, 1909.

30. Molinari, E.; Treatise on general and industrial inorganic chemistry. P. Blakiston's Son \& Co.: Philadelphia, 1912.

31. Newell, L. C.; General chemistry, D. C. Heath \& Co.: Boston, 1912

32. Newell, L. C.; General chemistry, D. C. Heath \& Co.: Boston, 1914.

33. Pond, G. G.; An outline of a course of instruction in general chemistry, $7^{\text {th }}$ ed., Lippincott: Philadelphia, 1912.

34. Blake, J. C.; General chemistry, theoretical and applied. Macmillan: New York, 1913.

35. Jones, H. C.; A new era in chemistry: some of the more important developments in general chemistry during the last quarter of a century, D. Van Nostrand Co.: New York, 1913.

36. McPherson, W.; Henderson, W. E.; A course in general chemistry, Ginn: Boston, 1913.

37. McPherson, W.; Henderson, W. E.; A course in general chemistry, Ginn: Boston, 1915.

38. McPherson, W.; Henderson, W. E.; A course in general chemistry, Ginn: Boston, 1917.

39. Cady, H. P.; General chemistry, McGraw-Hill: New York 1916.

40. Smith, A.; General chemistry for colleges, $2^{\text {nd }}$ ed., The Century Co.: New York, 1916.

41. Hildebrand, J. H.; Principles of chemistry, The Macmillan Co.: New York, 1918.

42. McCoy, H. N.; Terry, E. M.; Introduction to general chemistry, $2^{\text {nd }}$ ed., McGraw-Hill: New York, 1920.

43. Brownlee, R. B.; Elementary Principles of Chemistry. Allyn and Bacon: Boston, 1921.

44. Caven, R. M. The foundations of chemical theory: the elements of physical and general chemistry, Van Nostrand: New York 1921.

45. McPherson, W.; Henderson, W. E. A course in general chemistry. Boston: Ginn, 1921.

46. Holmes, H. N.; General chemistry, Macmillan Co.: New York, 1922.

47. Holmes, H. N.; General chemistry, Macmillan Co.: New York, 1925.

48. Deming, H. G.; General chemistry: an elementary survey emphasizing industrial applications of fundamental principles. J. Wiley \& Sons: New York, 1923. 
49. Deming, H. G.; General chemistry: an elementary survey, emphasizing industrial applications of fundamental principles, $2^{\text {nd }}$. ed., J. Wiley \& Sons: New York, 1925

50. Foster, W.; Introduction to general chemistry. Princeton University Press: Princeton, 1924.

51. Schlesinger, H. I.; General chemistry, Longmans, Green and Co.: New York, 1925

52. Brinkley, S. R.; Principles of general chemistry. Macmillan: New York, 1926

53. Kendall, J.; General chemistry: a cultural course based upon the texts of the late Alexander Smith, Century Co.: New York, 1927.

54. McCutcheon, T. P.; Seltz, H. General chemistry, theoretical and descriptive. D. Van Nostrand: New York, 1927.

55. Richardson, L. B.; General chemistry. H. Holt and Co.: New York, 1927.

56. Babor, J. A.; General chemistry; a text-book for college students. Thomas Y. Crowell: New York, 1929.

57. Hopkins, B. S.; General chemistry for colleges, D. C. Heath: Boston, 1930.

58. Foster, W.; An introduction to general chemistry, Princeton University Press: Princeton, 1931

59. Brinkley, S. R.; Introductory general chemistry. Macmillan: New York, 1932

60. Timm, J. A.; An introduction to chemistry, a pandemic text, $2^{\text {nd }}$ ed., McGraw-Hill: New York, 1932

61. Belcher, J. E.; Williams, G. Y.; Essentials of general chemistry, Semco Color Press: Oklahoma, 1934.

62. Bond, P. A.; The fundamentals of general chemistry, Farrar \& Rinehart: New York, 1935.

63. Briscoe, H. T.; General chemistry for colleges, Houghton Mifflin: Boston, 1935.

64. Dunbar, R. E.; Visual outline of general chemistry, Longmans: New York, 1939.
65. Irwin, F. C.; Sherwood, G. R.; General and inorganic chemistry, P. Blakiston's Son \& Co.: Philadelphia, 1939.

66. Sears, G. W.; Essentials of general chemistry: an introductory college course, International Textbook Co.: Scranton, 1939.

67. Babor, J. A.; Lehrman, A.; General college chemistry, Thomas Y. Crowell: New York, 1940.

68. Richardson, L. B.; Scarlett, A. J.; General college chemistry, H. Holt: New York, 1940.

69. Young, L. E.; Porter, C. W.; General chemistry; a first course. PrenticeHall: New York, 1940.

70. Brinkley, S. R.; Principles of general chemistry, $3^{\text {rd }}$ ed., Macmillan Co.: New York, 1941.

71. Massachusetts Institute of Technology (MIT); General chemistry: $5.01-$ 5.02. [S.1.]: [s.i.], 1943

72. Deming, H. G.; General chemistry: an elementary survey emphasizing industrial applications of fundamental principle, $5^{\text {th }}$ ed., J. Wiley \& Sons: New York, 1944

73. Sneed, M. C.; General college chemistry. D. Van Nostrand Co.: New York, 1944

74. Pauling, L.; General chemistry: an introduction to descriptive chemistry and modern chemical theory, Hayward, R., illust.; W. H. Freeman: San Francisco, 1947.

75. Currier, A. J.; Rose, A.; General and applied chemistry, a brief college course, McGraw-Hill: New York, 1948.

76. Laubengayer, A. W.; General chemistry, Rinehart: New York, 1949.

77. Sisler, H. H.; Van der Werf, C. A.; Davidson, A. W.; General chemistry, a systematic approach, Macmillan: New York, 1949

78. Partington, J. R.; General and inorganic chemistry for university students, $4^{\text {th }}$ ed., St. Martin's Press: New York, 1966; Partington, J. R.; General and inorganic chemistry for university students, $1^{\text {st.ed., St. }}$ Martin's Press: New York, 1946. 